\title{
A novel method to detect the Mexican founder mutation BRCAI ex9-12del associated with breast and ovarian cancer using quantitative polymerase chain reaction and TaqMan ${ }^{\circledR}$ probes
}

\author{
DENISSE AIDEÉ MARTÍNEZ-TREVIÑO ${ }^{1}$, RAFAEL BALTAZAR REYES LEÓN-CACHÓN ${ }^{1}$, \\ CYNTHIA VILLARREAL-GARZA ${ }^{2,3}$, DIONE AGUILAR Y MÉNDEZ ${ }^{2}$, \\ ELISA AGUILAR-MARTIINEZ ${ }^{4}$ and HUGO ALBERTO BARRERA-SALDAÑA ${ }^{5}$
}

\begin{abstract}
${ }^{1}$ Center of Molecular Diagnostics and Personalized Medicine, Department of Basic Sciences, Division of Health Sciences, University of Monterrey, San Pedro Garza Garcia, Nuevo Leon 66238; ${ }^{2}$ Breast Cancer Center, Monterrey Institute of Technology and Higher Education, Monterrey, Nuevo Leon 64710; ${ }^{3}$ Research Department, National Cancer Institute of Mexico, Ciudad de Mexico 14080, Mexico; ${ }^{4}$ Faculty of Biology, Medicine and Health, University of Manchester, M13 9PT Manchester, UK; ${ }^{5}$ TecSalud, Monterrey Institute of Technology and Higher Education, Monterrey, Nuevo Leon 64710, Mexico
\end{abstract}

Received December 5, 2017; Accepted April 20, 2018

DOI: $10.3892 / \mathrm{mmr} .2018 .9141$

\begin{abstract}
In 2015, according to the National Institute of Statistics and Geography (INEGI), malignant breast tumors were the first cause of cancer fatality in women 6,273 fatalities) in Mexico, whereas 2,793 fatalities in women were due to ovarian cancer. A total of 5-10\% of breast cancer and 10-15\% of ovarian cancer cases are caused by a hereditary breast-ovarian cancer syndrome, with mutations predominantly identified in the BRCA1 and BRCA2 genes. Recently, the Mexican founder mutation BRCA1 ex9-12del was identified (deletion of exons 9-12 with recombination between introns 8-12). This is the most frequently reported mutation in hereditary breast/ovarian cancer in Mexico. Current detection methods include end-point polymerase chain reaction (PCR) and Multiplex Ligation-dependent Probe Amplification (MLPA). In the present study a cheap, sensitive and fast detection method was developed based on quantitative PCR and two TaqMan ${ }^{\circledR}$ probes, one to detect the deletion (recombination region between introns 8 and 12), and the other one a region from exon 11 . With this assay, 90 samples were able to be analyzed in $2 \mathrm{~h}$ using $2.5 \mathrm{ng}$ of DNA/reaction at a cost of $\sim 2-3$ USD. This method is capable of detecting positive samples for DNA
\end{abstract}

Correspondence to: Dr Rafael Baltazar Reyes León-Cachón, Center of Molecular Diagnostics and Personalized Medicine, Department of Basic Sciences, Division of Health Sciences, University of Monterrey, 4500 Aveneu Ignacio Morones Prieto, Jesus M. Garza, San Pedro Garza Garcia, Nuevo Leon 66238, Mexico E-mail: rafael.reyesleon@udem.edu

Key words: BRCA1 ex9-12del mutation, real-time polymerase chain reaction, TaqMan ${ }^{\circledR}$ probes, $B R C A$ large rearrangements deletion and excluding negative ones. Therefore, the method proposed may be a useful high-throughput diagnostic option that could be useful in future association or prevalence studies that use large populations.

\section{Introduction}

Current diagnostic tools for detection of breast cancer have contributed to reduce its mortality. However, in 2015, the National Institute of Statistics and Geography (INEGI) in Mexico reported that breast cancer was the first cause of death among women between 35 and 44 years old (1). Additionally, ovarian cancer was within the top ten causes of cancer death in Mexican women (2).

Despite recent advances in science and new approaches for the detection of ovarian cancer through liquid biopsy, such as salivary samples, (3) in Mexico there are still no effective methods to reduce mortality due to ovarian cancer. Transvaginal ultrasound is the most commonly used technique but it might not always detect early stage abnormalities. In addition, there is no self-examination method as there is for breast cancer (4). In most cases, ovarian cancer is diagnosed when the tumor is already in an advanced stage.

Both breast and ovarian cancer share several risk factors, such as advanced age, nulliparity or having a full term pregnancy after 30-35 years old, family history of breast or ovarian cancer, mutations in BRCA1 and BRCA2 genes, early menarche, not having breastfed, late menopause and obesity (5-10). Among $5-10 \%$ of breast cancer and $10-15 \%$ of ovarian cancer cases are due to a hereditary mutation (11). Hereditary Breast and Ovarian Cancer syndrome (HBOC) is characterized by a high risk of developing breast or ovarian cancer (12). Most of the mutations found in HBOC are localized in the tumor suppressor genes $B R C A 1$ and $B R C A 2$, which participate in DNA repair. Carriers of a $B R C A 1$ mutation have a risk of 
$65-85 \%$ and $39-44 \%$ of developing breast and ovarian cancer, respectively, whereas having a $B R C A 2$ mutation confers a risk of $45-80 \%$ of developing breast cancer and $11-27 \%$ for ovarian cancer (11). Several mutations have been identified in specific populations, for example, in Ashkenazi Jews, the BRCAI mutations $185 \mathrm{delAG}$ and $8382 \mathrm{insC}$, and the BRCA2 mutation $6174 d e l T$ are found within $2-3 \%$ of the population (13). These mutations have been identified as founder mutations, because they were originated in a common ancestor and then inherited through generations (14). In 2007, the Mexican founder mutation BRCA1 ex9-12del, a deletion of exons 9-12 of around $14.7 \mathrm{~kb}$, was reported for the first time (15). Approximately, $42 \%$ of the $B R C A l$ gene is composed by Alu repetitive sequences, which can lead to errors during homologous recombination (16). Consequently, the BRCA1 ex9-12del mutation arises due to a recombination event between an $A l u S p$ element in intron 8 and an AluSx element in intron 12, with the subsequent loss of exons 9-12 (15).

BRCA1 ex9-12del mutation was first documented in a sample of women with Hispanic ancestry and family history of breast and ovarian cancer. The deletion was found in four non-related families, all of them with Mexican ancestry (15). The same research group performed another study in Hispanics, in which individuals with personal or family cancer history were shown to have BRCA mutations; 21 of 189 were specifically large rearrangement (LR) mutations, in which 13 were carriers of the BRCAl ex9-12del mutation (17). In a different study involving Mexican women with breast or ovarian cancer, the BRCA1 ex9-12del mutation was present in $35 \%$ of ovarian cancer cases associated with $B R C A$ and in $29 \%$ of breast cancer cases associated with BRCA (18). In a later study where only women with breast cancer participated, the deletion was found in $24 \%$ of cases associated with BRCA mutations, in patients between 35 and 56 years old (19). A more recent report showed that the $B R C A 1$ ex9-12del mutation represented $42 \%$ of the cases with $B R C A$ mutations among young Mexican women diagnosed with triple negative breast cancer (20). Regarding the origin of the BRCA1 ex9-12del mutation, it has been suggested that it arose 1480 years ago (95\% CI, 920-2260 years) in Puebla, Mexico (17). Studies performed in high breast cancer risk individuals from Spain, Colombia, Germany and Pakistan, have shown the absence of the mutation in those populations $(21,22)$. Moreover, reports from Myriad Genetic Laboratories (Salt Lake City, UT) indicated that patients with HBOC of Latin American/Caribbean ancestry commonly carry large rearrangements $(21.4 \%$ of all $B R C A$ mutations). In these reports, the Mexican founder mutation BRCA1 ex9-12del accounted for 37\% of those LR (23).

Taken together, these data show the high frequency of the BRCA1 ex9-12del mutation among young Mexican women with HBOC. Therefore, the detection of this deletion in relatives of the mutation carriers might encourage strategies for early detection and prevention of breast and ovarian cancer, such as recurrent clinical and imaging examinations, lifestyle modifications or prophylactic surgeries and/or chemoprevention use. Moreover, analyzing the presence of this deletion in Mexican patients suspicious of carrying a $B R C A$ mutation will definitely be a cheaper option, before searching for mutations and LR in complete BRCA genes. Sequencing of both $B R C A$ genes costs $\sim 1,000-4,000$ USD (24). Myriad Genetic
Laboratories currently uses quantitative multiplex endpoint polymerase chain reaction (PCR) to detect a set of common LR, including the BRCA1 ex9-12del mutation, at a cost of 700 USD, under the name BRACAnalysis Large Rearrangement Test (BART) (23,25). Unfortunately, most Mexican patients do not have access to such expensive tests. Other techniques can be used to detect LR, for example Multiplex Ligation-dependent Probe Amplification (MLPA), Protein Truncation Test (PTT), long range PCR, Fluorescence In Situ Hybridization and end-point PCR (26). However, these techniques can be time consuming, difficult to interpret and expensive since different equipment and reagents are required. Most of the research papers that have screened patients for the BRCA1 ex9-12del mutation have used end-point PCR $(15,18,20)$, MLPA (19) and one included the Myriad diagnostic test (17).

The aim of the present study was to develop a new method to detect the Mexican founder mutation BRCA1 ex9-12del by qPCR and TaqMan ${ }^{\circledR}$ probes. The method we propose is economic, specific, sensitive, fast, easy to interpret, and it can be used in both research and diagnostic scenarios.

\section{Materials and methods}

Study samples. A total of four DNA samples from previously known carriers of the BRCA1 ex9-12del mutation were obtained, three from the Hospital Zambrano Hellion TecSalud and one from the Laboratorio Nacional Biobanco. Control samples were obtained from six female volunteers without a family history of cancer, who work at the Universidad de Monterrey. Three $\mathrm{ml}$ of peripheral blood were collected in a tube with EDTA. The study complied with the guidelines of the Declaration of Helsinki and was approved by the Research and Ethics Committee from the University of Monterrey (registration no. 01072017-CIE). Written informed consent was obtained from all subjects.

DNA extraction. The Wizard Genomic DNA Purification kit (Promega Corp., Madison, WI, USA) was used to isolate DNA from the six volunteers' blood samples. DNA extraction was performed according to manufacturer's instructions. Genomic DNA was quantified by UV absorbance using Nanodrop (Thermo Fisher Scientific, Inc., Wilmington, MA, USA). The DNA quality was evaluated with the A260/280 and A260/230 ratios. Samples were stored at $-20^{\circ} \mathrm{C}$.

Characterization of the recombination region between introns 8 and 12 of BRCA1. The key contribution of our work was the design of a TaqMan ${ }^{\circledR}$ probe which is complementary to the recombination region between introns 8 and 12 of $B R C A 1$, for the detection of the BRCA1 ex9-12del mutation. In order to achieve this, the first step was to identify the DNA sequence of the recombination site. Therefore, an end-point PCR assay was designed (Fig. 1), and then the PCR product was sequenced. The DNA of a sample from a BRCA1 ex9-12del mutation carrier was amplified using the Go-taq flexi DNA polymerase kit (Promega Corp.). The PCR was carried out in a total volume of $15 \mu \mathrm{l}$ containing $100 \mathrm{ng}$ of DNA, $1 \mathrm{X}$ buffer, $1.5 \mathrm{nM} \mathrm{MgCl}_{2}$, $0.2 \mathrm{mM}$ dNTPs, $0.2 \mu \mathrm{M}$ primer $\mathrm{F}, 0.2 \mu \mathrm{M}$ primer $\mathrm{R}, 1.25$ units of DNA polymerase and nuclease-free water. Initial denaturation was set at $94^{\circ} \mathrm{C}$ for $3 \mathrm{~min}$, then 30 cycles of denaturation at $94^{\circ} \mathrm{C}$ 

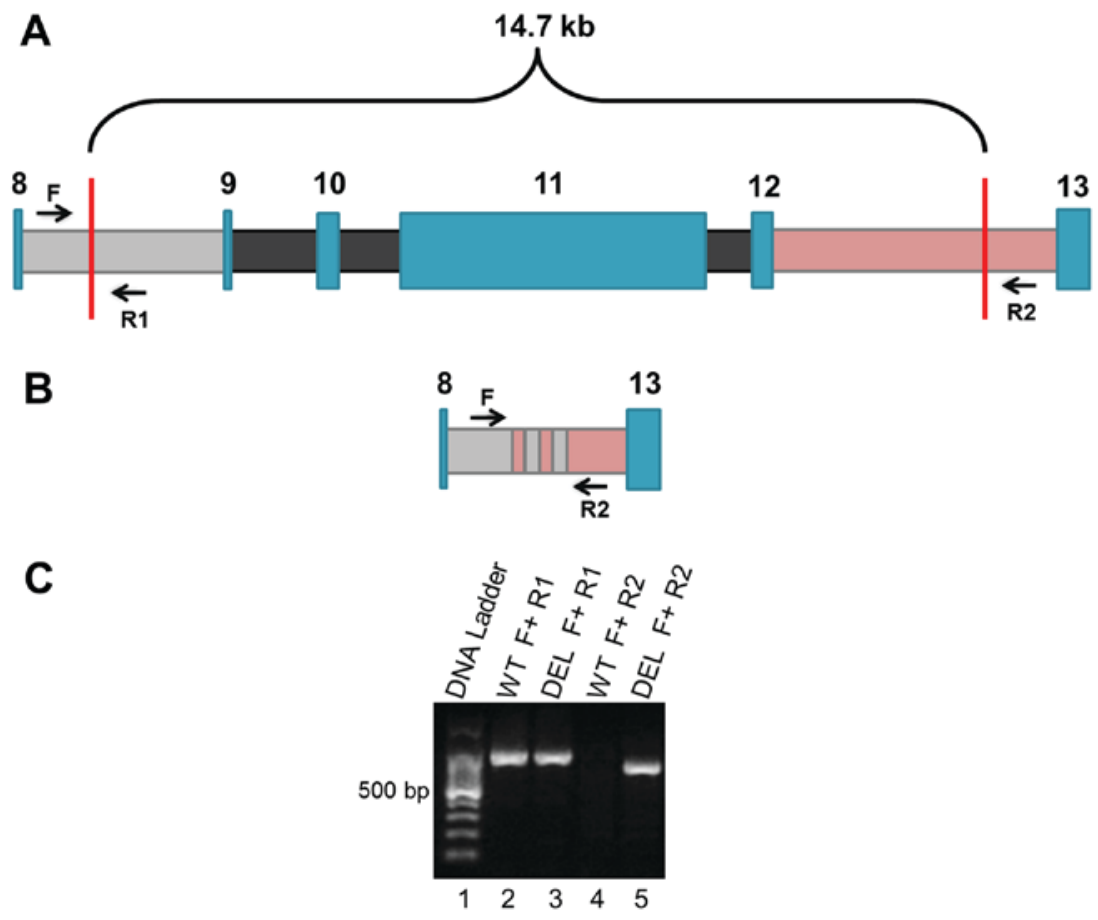

Figure 1. Location of the BRCA1 ex9-12del mutation and design of the end-point PCR method for its detection. (A) Wild-type allele of the $B R C A 1$ gene showing exons (blue color) and introns (8 gray color; 9,10 and 11 black color, 12 pink color). In the BRCA1 ex9-12del mutation, the missing DNA includes exons 9 to $12(14.7 \mathrm{~kb})$ in one single copy of the gene (heterozygous), having the breakpoint somewhere in introns 8 and 12 (vertical red lines). Black arrows indicate the design and position of the primers used for the end-point PCR assay (F, R1 and R2). (B) Variant allele with the deletion of exons 9-12 and the recombination of introns 8 and 12 (pink/gray zone). Black arrows indicate position of primers F and R2. (C) Agarose gel electrophoresis after the end-point PCR of a sample carrying the mutation (DEL) and a wild-type sample (WT). Lane 1, DNA ladder. Lanes 2 and 3 represent the amplification of samples WT and DEL with primers F and R1, showing an amplified product corresponding to a region of the wild-type allele ( $\sim 840$ bp). Lanes 4 and 5 are the PCR products of a WT sample and a DEL sample respectively, with primers F and R2, amplifying the allele with deletion only ( $\sim 630$ bp). This PCR fragment can be seen only in samples DEL. Primers F and R2 in a wild-type allele would give an amplified PCR product $>14.47 \mathrm{~kb}$, an impossible task for our end-point PCR. PCR, polymerase chain reaction.

for $30 \mathrm{sec}$, annealing $40 \mathrm{sec}$ at $60^{\circ} \mathrm{C}$ for primers $\mathrm{F}$ and $\mathrm{R} 1$ or at $55^{\circ} \mathrm{C}$ for primers $\mathrm{F}$ and $\mathrm{R} 2$, extension at $72^{\circ} \mathrm{C}$ for $1 \mathrm{~min}$. $\mathrm{A}$ final extension was included at $72^{\circ} \mathrm{C}$ for $5 \mathrm{~min}$. The reaction was performed in a Thermocycler Eppendorf Mastercycle EP gradient S Thermal (Eppendorf, Hamburg, Germany). The PCR products were analyzed by electrophoresis on a $1.5 \%$ agarose gel and stained with GelGreen ${ }^{\mathrm{TM}}$ (Biotium, Fremont, CA, USA). Primers were designed using the BRCA1 DNA sequence with accession no. L78833.1 from the GenBank of the National Center of Biotechnology Information (NCBI; https://www. ncbi.nlm.nih.gov/nuccore/1698398/).

Sequencing of the recombination region between introns 8 and 12 of BRCA1. The PCR product amplified with primers $\mathrm{F}$ and $\mathrm{R} 2$ of a sample from a $B R C A 1$ ex9-12del mutation was purified with QIAquick kit (Qiagen, Hilden, Germany) following manufacturer's instructions. The sample was sequenced in a Genetic Analyzer 3100 (Thermo Fisher Scientific, Inc.) by an external supplier, the Instituto Potosino de Investigación Científica y Tecnológica (IPICYT, San Luis Potosí, Mexico). Sequences were analyzed with CodonCode Aligner software (CodonCode Corp., Centerville, MA, USA). The obtained recombination sequence was the same as the one previously published in 2007 when the $B R C A 1$ ex9-12del mutation was reported (15).

Design of the qPCR primers and TaqMan ${ }^{\circledR}$ probes. Using the recombination sequence, primers were designed to amplify a 164 bp fragment flanking this recombination site. Therefore, the $\mathrm{F}$ primer was designed to bind to a sequence in intron 8 , and the $\mathrm{R}$ primer to intron 12 . Melting temperature of both primers was $60^{\circ} \mathrm{C}$. Primers were tested in samples with the $B R C A 1$ ex9-12del mutation, resulting in the amplification of a single 164 bp DNA fragment. The TaqMan ${ }^{\circledR}$ probe complementary to the recombination region was designed using the software Custom qPCR Probes from Integrated DNA Technologies (IDT, Coralville, IA, USA). The probe was ordered with FAM $^{\mathrm{TM}}$ dye and the quenchers $\mathrm{ZEN}^{\mathrm{TM}} / \mathrm{IB}^{\circledR} \mathrm{FQ}$.

As a DNA control, a PCR was included to amplify a region of exon 11 from BRCA1. Design of primers and TaqMan ${ }^{\circledR}$ probe specific for exon 11 was carried out using the reference sequence (L78833.1) the same way as for the BRCA1 ex9-12del mutation, but $\mathrm{HEX}^{\mathrm{TM}}$ dye was used instead.

qPCR with designed primers and TaqMan ${ }^{\circledR}$ probes. Thermocycler StepOnePlus ${ }^{\mathrm{TM}}$ Real-Time PCR System (Thermo Fisher Scientific, Inc.) was used to perform the qPCR with TaqMan ${ }^{\circledR}$ probes. The PCR was prepared with 1X TaqMan ${ }^{\circledR}$ Universal PCR Master Mix (Thermo Fisher Scientific, Inc.), $0.2 \mu \mathrm{M}$ primer F, $0.2 \mu \mathrm{M}$ primer $\mathrm{R}, 250 \mathrm{nM}$ probe, $10 \mathrm{ng}$ DNA, and nuclease-free water to a total volume of $15 \mu \mathrm{l}$. Thermal cycling conditions were as follows: $60^{\circ} \mathrm{C}$ for $30 \mathrm{sec}, 50^{\circ} \mathrm{C}$ for $2 \mathrm{~min}, 95^{\circ} \mathrm{C}$ for $10 \mathrm{~min}, 40$ cycles of $95^{\circ} \mathrm{C}$ for $15 \mathrm{sec}$ and $60^{\circ} \mathrm{C}$ for $1 \mathrm{~min}$. A final post-read method was set 


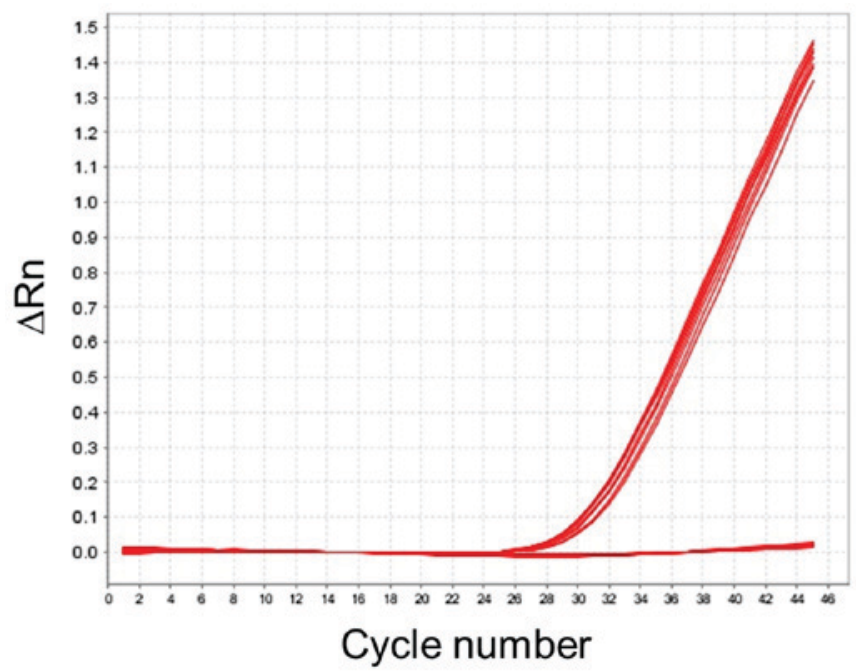

Figure 2. Detection of the BRCA1 ex9-12del mutation by real-time PCR and $\mathrm{TaqMan}^{\circledR}$ probe. Red amplification curves represent the fluorescent signal given by the $\mathrm{FAM}^{\mathrm{TM}}$ dye from the TaqMan ${ }^{\circledast}$ probe detecting the variant allele in the four positive samples, which had a mean Ct of 27.46. No amplification curve is observed for the negative samples neither for negative controls (horizontal red lines). The ' $\mathrm{Y}$ ' axis values represent the fluorescent signal normalized of the $\mathrm{FAM}^{\mathrm{TM}}$ dye with the ROX, whereas the ' $\mathrm{X}$ ' axis represent number of cycles. PCR. PCR, polymerase chain reaction; ROX, passive reference dye.

at $60^{\circ} \mathrm{C}$ for $30 \mathrm{sec}$. The passive reference dye included in the TaqMan ${ }^{\circledR}$ Universal Master Mix was ROX.

Analysis of results. The fluorescent signal of the TaqMan ${ }^{\circledR} \mathrm{qPCR}$ was analyzed using the StepOnePlus ${ }^{\mathrm{TM}}$ software v2.3 (Thermo Fisher Scientific, Inc.) under presence/absence and genotyping methods. In the presence/absence analysis, a positive result for a deleterious mutation (BRCA1 ex9-12del) was the amplification signal of the recombination region given by the probe carrying the FAM $^{\mathrm{TM}}$ dye, displayed in an amplification plot. We considered a positive signal at a $\mathrm{Ct}$ between 27 and 27.5. As a control we used the amplification signal of the exon 11 given by the probe carrying the $\mathrm{HEX}^{\mathrm{TM}}$ dye.

TaqMan ${ }^{\circledR}$ Genotyper software was used to analyze raw data from qPCR in an allelic discrimination (AD) plot. The regular AD plot shows each sample well as an individual dot. The AD plot can show different clusters of dots such as homozygous and heterozygous samples, no-template controls (NTC) and undetermined samples. The dots of each cluster are grouped closely and each cluster is located far from the others. In a typical AD plot, the cluster of homozygous samples for allele 1 labeled with $\mathrm{HEX}^{\mathrm{TM}}$ dye is located in the lower right corner. The cluster of homozygous samples for the allele 2 labeled with FAM $^{\mathrm{TM}}$ dye is located in the upper left corner and the cluster of heterozygous (allele 1/allele 2) samples is located approximately midway between both homozygous clusters. NTC samples are located in the lower left corner. The undetermined samples are represented by an X and are located in any region of the AD plot outside of the described above. Nonetheless, the clusters displayed in the AD plot from our TaqMan ${ }^{\circledR} \mathrm{qPCR}$ assay are different, as explained below. Carriers of at least a single copy of the wild-type allele (exon 11) are located in the lower right corner $\left(\mathrm{HEX}^{\mathrm{TM}}\right)$. Carriers of at least one allele with

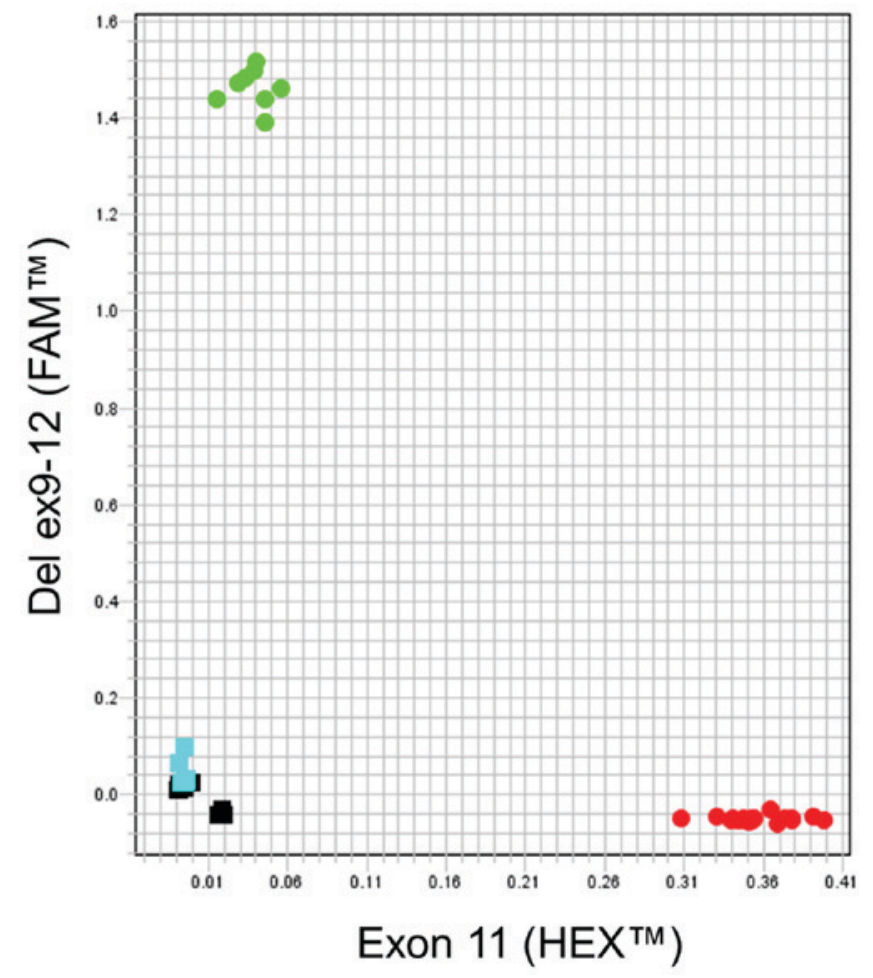

Figure 3. Genotyping assay for the detection of the mutant allele (with the $B R C A 1$ ex9-12del mutation) and the wild-type allele (exon 11) by real-time PCR and TaqMan ${ }^{\circledR}$ probes. The AD plot shows 2 groups; green color samples have the allele with the deletion, samples in red color possess exon 11 or the wild-type allele (in this group all the samples are present, the 6 negative and the 4 positive ones). Samples in blue color are negative samples for the deletion, which have no fluorescence and are classified by the software as negatives. Negative controls are shown in black squares. Each sample was processed by duplicate. The axis values represent relative fluorescence $(\Delta R n)$ between both dyes (FAM ${ }^{\mathrm{TM}}$ for the mutant allele and $\mathrm{HEX}^{\mathrm{TM}}$ for the wild-type allele). PCR, polymerase chain reaction; $\mathrm{AD}$, allelic discrimination.

the BRCA1 ex9-12del mutation are clustered in the upper left corner $\left(\mathrm{FAM}^{\mathrm{TM}}\right)$.

\section{Results}

DNA samples. A total of ten DNA samples were subjected to different experiments in order to detect the BRCA1 ex9-12del mutation. Four of them were previously known as carriers of the BRCAl ex9-12del mutation, three obtained from females and one from a male. Three of these samples of mutation carriers were family members (mother, daughter and son) and one from an unrelated female. Samples used as controls were obtained from six unrelated females not suspected to carry the BRCA1 ex9-12del mutation.

End-point PCR. Positive and negative samples of the BRCAl ex9-12del mutation were analyzed with the end-point PCR method. A unique band of $~ 630$ bp was observed in the agarose gel with primers $\mathrm{F}$ and $\mathrm{R} 2$ in the four positive samples. This band was not observed in the six negative samples (Fig. 1).

qPCR with TaqMan ${ }^{\circledR}$ probes using the presencelabsence method. The thermocycler allows performing a PCR under different types of methods, such as presence/absence, genotyping and relative standard curve. The positive and negative 
Table I. Comparison between qPCR, end-point PCR and MLPA techniques for the detection of the BRCA1 ex9-12del mutation $(15,31,36,37,38)$.

\begin{tabular}{lccc}
\hline Variable & $\begin{array}{c}\text { qPCR and } \\
\text { TaqMan }{ }^{\circledR} \text { probes }\end{array}$ & End-point PCR & MLPA \\
\hline Required equipment & $\begin{array}{c}\text { Real-time PCR } \\
\text { thermocycler }\end{array}$ & $\begin{array}{c}\text { Conventional PCR thermocycler, } \\
\text { electrophoresis chambers, electrophoresis } \\
\text { power supply, microwave oven and UV }\end{array}$ & $\begin{array}{c}\text { Conventional PCR thermocycler } \\
\text { and capillary sequencer. }\end{array}$
\end{tabular}
transilluminator to visualize agarose gels.

Amount of DNA

required per reaction

Processing time

until results (excluding

DNA extraction) Sample number

to be simultaneously processed

(fitting to the processing time)

\section{$2.5 \mathrm{ng}$}

$2 \mathrm{~h}$

90 $\geq 80 \mathrm{ng}$

$3.5 \mathrm{~h}$

25
50-250 ng

$24 \mathrm{~h}$

96

qPCR, quantitative polymerase chain reaction; MLPA, multiplex ligation-dependent probe amplification; UV, ultraviolet.

samples of the BRCAl ex9-12del mutation were analyzed with $\mathrm{qPCR}$ and the $\operatorname{TaqMan}^{\circledR}$ probe complementary to the recombination region under the presence/absence method. Four DNA samples showed amplification signal from FAM ${ }^{\mathrm{TM}}$ dye, indicating the presence of the BRCA1 ex9-12del mutation. These positive samples showed amplification curves at $\mathrm{Ct}$ mean 27.46 (Fig. 2). This signal was absent in the six control samples.

qPCR with TaqMan ${ }^{\circledR}$ probes using the genotyping method. In order to identify heterozygous from homozygous carriers in a single analysis, the ten DNA samples were tested by the genotyping method. Six subjects showed fluorescent signal only from $\mathrm{HEX}^{\mathrm{TM}}$ dye, meaning they carry only the wild-type allele (exon 11). In the AD plot, these samples are located in a single cluster in the lower right corner (Fig. 3). Four subjects showed both fluorescent signals, from $\mathrm{HEX}^{\mathrm{TM}}$ and $\mathrm{FAM}^{\mathrm{TM}}$ dyes, indicating the presence of exon 11 and the BRCA1 ex9-12del mutation, respectively. Thereby, these are heterozygous samples which were located in two clusters, one corresponding to the $\mathrm{HEX}^{\mathrm{TM}}$ signal (lower right corner) and one to the $\mathrm{FAM}^{\mathrm{TM}}$ signal (duplicates in the upper left corner) (Fig. 3).

\section{Discussion}

Currently, different methods are used for the early detection of cancer, such as analysis of circulating tumor cells (CTCs), as well as RNA exosomes (27), proteins (3) and genomic profiles of circulating cell-free tumor DNA (ctDNA) from liquid biopsy $(27,28)$. Although the application of these methods can be useful to improve prognosis, there are still some limitations (28). For example, they are more effective for early detection of certain types of cancer, such as ovarian cancer, but less effective to detect breast cancer (29). Therefore, there are no well-defined biomarkers for all types of cancer (28). However, the effectiveness of breast cancer detection can be improved by including tests that identify mutations in the $B R C A$ genes (30).
The inclusion of $B R C A$ screening in the health care system is highly affected by the cost of $B R C A$ testing (30). Therefore, it would be desirable to have alternative low-cost options for the detection of mutations. The proposed method for the detection of the BRCA1 ex9-12del mutation is based on qPCR and TaqMan ${ }^{\circledR}$ probes. This method was capable of detecting four positive BRCA1 ex9-12del mutation carriers, which were previously analyzed by our end-point PCR method. This was the expected result, since the probe was designed to be complementary to the mutant allele, specifically in the recombination region between introns 8 and 12, which is a unique sequence in the human DNA.

Among the main advantages of this method is the low cost, which is 2-3 USD per sample, compared to a price of 500 USD for the determination of a specific mutation. High prices are a limitation for those who wish to know their genetic status regarding BRCA1 ex9-12del mutation. Using qPCR allows high sensitivity since the reaction can be carried out only with $2.5 \mathrm{ng}$ of DNA (31). In addition, a TaqMan ${ }^{\circledR}$ probe allows high specificity since it binds only to the sequence to which is complementary, even if a single base pair differs from the probe and the DNA region. The fact that a small amount of DNA is required for the assay gives an extra strength to this method, since DNA can be extracted from small biological samples taken in a non-invasive manner, such as urine, epithelial cells from the mouth or hair roots. Peripheral blood guarantees a high DNA yield, but its extraction is painful and uncomfortable for the patient, especially when the quality of the veins is not good due to prior chemotherapy. It is a fast method since in $2 \mathrm{~h}$ a total of 90 samples can be analyzed in a single experiment, including the interpretation.

Biallelic mutations in both $B R C A$ genes are rare $(32,33)$. Therefore, deleterious mutations in these genes are mainly heterozygous (34). However, biallelic pathogenic mutations have been reported in individuals with ovarian cancer. Nevertheless, those patients are compound heterozygous, this is, they carry mutations in both $B R C A 1$ copies, but in different regions (for example: c.2457delC/c.5207T>C) (33). Biallelic 
mutations in BRCA genes could increase the risk of cancer, as well as leading to more severe phenotypes $(32,35)$. To date, no individual has been found homozygous for the $B R C A I$ ex9-12del mutation. Most probably the latter would not be compatible with life since great quantity of genetic material is lost. However, it is important to detect any region of the wild-type allele at the same time that we detect the mutant allele. This is also helpful as a control of DNA presence in the sample. Consequently, we also designed an assay based on qPCR and a TaqMan ${ }^{\circledR}$ probe to detect a region from exon 11 of BRCAl.

When performing a TaqMan ${ }^{\circledR}$ qPCR run under the genotyping method, the amplification of both variant and wild-type alleles is ideally carried out in the same reaction well; this is, in a multiplex fashion. Nonetheless, in our study, we performed the PCR of the variant allele and the PCR of the wild-type allele in separate reaction wells. So, a sample will be defined as heterozygous only if it appears in both clusters in the AD plot (Fig. 3). Consequently, as future study, we aim to standardize a multiplex qPCR capable of detecting the variant allele (recombination region) and the wild-type allele (a region from exons 9 to 12) in one single reaction, saving time and reagents.

Since BRCA1 ex9-12del mutation is considered as a founder mutation, and the existing reports have shown that the recombination region is the same among all carriers of this mutation; our method is considered highly specific because the TaqMan ${ }^{\circledR}$ probe binds to this recombination DNA sequence. However, if a different recombination region is discovered, or if any additional mutations arise in this region, our method would have to be modified accordingly and readapted to the newly reported genetic variants.

Compared to the reported methods used to detect the BRCA1 ex9-12del mutation, our propose represents a suitable option for testing given the advantages already mentioned.

The software of the qPCR thermocycler analyzes the results at the end of the run, displaying the presence or absence of the mutation and therefore, making the interpretation an easy step. Moreover, working with qPCR avoids the risk of post-amplification contamination, since only one process is needed. On the other hand, end-point PCR requires a first step of amplification, followed by the run of the samples on an agarose gel, a process in which the samples can be cross-contaminated (36). Comparing to the PCR method reported by Weitzel et al, in 2007 (15), our design requires less DNA input, $2.5 \mathrm{ng}$ (31), whereas the Weitzel method requires 50-100 ng. Additionally, it does not require further manipulation of the sample, for example purification of the amplified product, sequencing-PCR and capillary electrophoresis. The analysis of results is faster and the identification of the heterozygous carriers is an easier task (15). Another method used to detect deletions is MLPA, which has the great advantage of detecting more than one mutation since it analyzes different regions of the genome simultaneously. However, for the detection of the BRCA1 ex9-12del mutation, this method has the disadvantage of requiring a large amount of DNA input (250-450 ng), increased sample handling, carrying an additional risk of cross-contamination. It also requires capillary sequencer and the analysis is more complex (37) compared to our TaqMan ${ }^{\circledR}$ real-time method. A comparison between current methods for the detection of the BRCA1 ex9-12del mutation is summarized in Table I.

The method we propose will allow the determination of a high number of samples at the same time, which will be a great advantage in future studies of association or prevalence. Additionally, it is a safe, specific and more affordable option for those wishing to be tested for the mutation.

\section{Acknowledgements}

The authors would like to thank Professor Marcelino Aguirre Garza from Center of Molecular Diagnostics and Personalized Medicine, Department of Basic Sciences, Division of Health Sciences, University of Monterrey, San Pedro Garza Garcia, Nuevo Leon, Mexico, for performing the blood extraction procedure of the participants.

\section{Funding}

The present study was supported by the University of Monterrey (grant no. UIN-17528).

\section{Availability of data and materials}

The datasets used and/or analyzed during the current study are available from the corresponding author on reasonable request.

\section{Authors' contributions}

DAMT designed the sequences of primers and probes, performed DNA isolation, PCR experiments and wrote the manuscript. RBRLC conceived the study, directed, planned and analyzed the data and wrote manuscript. CVG and DAM performed the participants' selection, clinical evaluation and interpreted the results. EAM and HABS analyzed the data, interpreted the results and critically reviewed the manuscript.

\section{Ethics approval and consent to participate}

The protocol was approved by Ethics, Research and Biosecurity Committees of the University of Monterrey, San Pedro Garza Garcia, Nuevo Leon, Mexico, registry no. 01072017-CIE. Written informed consent was obtained from all subjects.

\section{Consent for publication}

Not applicable.

\section{Competing interests}

The authors declare that they have no competing interests.

\section{References}

1. National Institute of Statistics and Geography (INEGI): Main causes of mortality by habitual residence, age groups and gender of the deceased. Query results: Basic tabulations. INEGI, Mexico City, 2015. http://www.inegi.org.mx/est/contenidos/proyectos/ registros $/$ vitales $/ \mathrm{mortalidad} /$ tabulados $/ \mathrm{pc}$.asp? $\mathrm{t}=14 \& \mathrm{c}=11817$. Accessed November 15, 2017. 
2. National Institute of Statistics and Geography (INEGI) General Mortality. INEGI, Mexico City, 2015. http://www. inegi.org.mx/sistemas/olap/Proyectos/bd/continuas/mortalidad/ MortalidadGeneral.asp. Accessed November 15, 2017

3. Tajmul M, Parween F, Singh L, Mathur SR, Sharma JB, Kumar S, Sharma DN and Yadav S: Identification and validation of salivary proteomic signatures for non-invasive detection of ovarian cancer. Int J Biol Macromol 108: 503-514, 2018.

4. Doubeni CA, Doubeni AR and Myers AE: Diagnosis and management of ovarian cancer. Am Fam Physician 93: 937-944, 2016.

5. Aguilar-Cordero MJ, González-Jimenez M, Álvarez-Ferre J, Padilla-López CA, Mur-Villar N, García-López PA and Valenza-Peña MC: Breast feeding: An effective method to prevent breast cancer. Nutr Hosp 25: 954-958, 2010 (In Spanish).

6. Lacey JV Jr, Kreimer AR, Buys SS, Marcus PM, Chang SC Leitzmann MF, Hoover RN, Prorok PC, Berg CD and Hartge P, Prostate, Lung, Colorectal and Ovarian (PLCO) Cancer Screening Trial Project Team: Breast cancer epidemiology according to recognized breast cancer risk factors in the Prostate, Lung, Colorectal and Ovarian (PLCO) Cancer Screening Trial Cohort. BMC Cancer 9: 84, 2009.

7. Ligibel J: Obesity and breast cancer. Oncology (Williston Park) 25: 994-1000, 2011

8. Luan NN, Wu QJ, Gong TT, Vogtmann E, Wang YL and Lin B: Breastfeeding and ovarian cancer risk: A meta-analysis of epidemiologic studies. Am J Clin Nutr 98: 1020-1031, 2013.

9. Reid BM, Permuth JB and Sellers TA: Epidemiology of ovarian cancer: A review. Cancer Biol Med 14: 9-32, 2017.

10. Russo J, Balogh GA and Russo IH: Full-term pregnancy induces a specific genomic signature in the human breast. Cancer Epidemiol Biomarkers Prev 17: 51-66, 2008.

11. Cárdenas-Sánchez J, Bargalló-Rocha E, Erazo-Valle A, Maafs-Molina E and Poitevin-Chacón A: Mexican Consensus on diagnosis and treatment of breast cancer. 5th revision. Masson Doyma México S.A, Mexico City, 2013.

12. McCarthy AM and Armstrong K: The role of testing for BRCA1 and BRCA2 mutations in cancer prevention. JAMA Intern Med 174: 1023-1024, 2014.

13. Levy-Lahad E, Catane R, Eisenberg S, Kaufman B, Hornreich G, Lishinsky E, Shohat M, Weber BL, Beller U, Lahad A and Halle D: Founder BRCA1 and BRCA2 mutations in Ashkenazi Jews in Israel: Frequency and differential penetrance in ovarian cancer and in breast-ovarian cancer families. Am J Hum Genet 60: 1059-1067, 1997.

14. Narod SA and Rodríguez AA: Genetic predisposition for breast cancer. BRCA1 and BRCA2 genes. Salud Publica Mex 53: 420-429, 2011

15. Weitzel JN, Lagos VI, Herzog JS, Judkins T, Hendrickson B, Ho JS, Ricker CN, Lowstuter KJ, Blazer KR, Tomlinson G and Scholl T: Evidence for common ancestral origin of a recurring BRCA1 genomic rearrangement identified in high-risk Hispanic families. Cancer Epidemiol Biomarkers Prev 16: 1615-1620, 2007.

16. Smith TM, Lee MK, Szabo CI, Jerome N, McEuen M, Taylor M, Hood L and King MC: Complete genomic sequence and analysis of $117 \mathrm{~kb}$ of human DNA containing the gene BRCA1. Genome Res 6: 1029-1049, 1996.

17. Weitzel JN, Clague J, Martir-Negron A, Ogaz R, Herzog J, Ricker C, Jungbluth C, Cina C, Duncan P, Unzeitig G, et al: Prevalence and type of BRCA mutations in Hispanics undergoing genetic cancer risk assessment in the southwestern United States: A report from the Clinical cancer genetics community research network. J Clin Oncol 31: 210-216, 2013.

18. Villarreal-Garza C, Alvarez-Gomez RM, Perez-Plasencia C, Herrera LA, Herzog J, Castillo D, Mohar A, Castro C, Gallardo LN, Gallardo D, et al: Significant clinical impact of recurrent BRCA1 and BRCA2 mutations in Mexico. Cancer 121: 372-378, 2015.

19. Torres-Mejia G, Royer R, Llacuachaqui M, Akbari MR, Giuliano AR, Martinez-Matsushita L, Angeles-Llerenas A, Ortega-Olvera C,ZivE,Lazcano-PonceE, et al:RecurrentBRCA1 and BRCA2 mutations in Mexican women with breast cancer. Cancer Epidemiol Biomarkers Prev 24: 498-505, 2015.

20. Villarreal-Garza C, Weitzel JN, Llacuachaqui M, Sifuentes E, Magallanes-Hoyos MC, Gallardo L, Alvarez-Gomez RM, Herzog J, Castillo D, Royer R, et al: The prevalence of BRCA1 and BRCA2 mutations among young Mexican women with triple-negative breast cancer. Breast Cancer Res Treat 150: 389-394, 2015.
21. de la Hoya M, Gutierrez-Enriquez S, Velasco E, Osorio A, Sanchez de Abajo A, Vega A, Salazar R, Esteban E, Llort G, Gonzalez-Sarmiento R, et al: Genomic rearrangements at the BRCA1 locus in Spanish families with breast/ovarian cancer. Clin Chem 52: 1480-1485, 2006.

22. Torres D, Rashid MU, Seidel-Renkert A, Weitzel JN, Briceno I and Hamann U: Absence of the BRCA1 del (exons 9-12) mutation in breast/ovarian cancer families outside of Mexican Hispanics. Breast Cancer Res Treat 117: 679-681, 2009.

23. Judkins T, Rosenthal E, Arnell C, Burbidge LA, Geary W, Barrus T, Schoenberger J, Trost J, Wenstrup RJ and Roa BB: Clinical significance of large rearrangements in BRCA1 and BRCA2. Cancer 118: 5210-5216, 2012.

24. Cartwright-Smith L: Patenting genes: What does Association for Molecular Pathology v. Myriad Genetics mean for genetic testing and research? Public Health Rep 129: 289-292, 2014.

25. Myriad. BRACAnalysis ${ }^{\circledR}$ Large Rearrangement Test (BART) FAQ. https://webapps.myriad.com/lib/brac/BART-faq.pdf. Accessed November 30, 2017

26. Ewald IP, Ribeiro PL, Palmero EI, Cossio SL, Giugliani R and Ashton-Prolla P: Genomic rearrangements in BRCA1 and BRCA2: A literature review. Genet Mol Biol 32: 437-446, 2009.

27. Siravegna G, Marsoni S, Siena S and Bardelli A: Integrating liquid biopsies into the management of cancer. Nat Rev Clin Oncol 14: 531-548, 2017

28. National Cancer Institute (NCI), National Institute of Health (NHI). Liquid Biopsy: Using DNA in blood to detect, track and treat cancer. NCI Staff, United States, 2017. https://www.cancer. gov/news-events/cancer-currents-blog/2017/liquid-biopsy-detectstreats-cancer. Accessed February 12, 2018.

29. Cohen JD, Li L, Wang Y, Thoburn C, Afsari B, Danilova L, Douville C, Javed AA, Wong F, Mattox A, et al: Detection and localization of surgically resectable cancers with a multi-analyte blood test. Science 359: 926-930, 2018.

30. D'Andrea E, Marzuillo C, De Vito C, Di Marco M, Pitini E, Vacchio MR and Villari P: Which BRCA genetic testing programs are ready for implementation in health care? A systematic review of economic evaluations. Genet Med 18: 1171-1180, 2016.

31. Martinez-TrevinoDA,Moreno-TrevinoMG,Salinas-SantanderM, Wohn L, Herrera-Gonzalez S, Aguirre-Garza M, Rojas OC and Leon-Cachon RB: Rapid Detection of the GSTM3 A/B polymorphism using real-time PCR with TaqMan ${ }^{\circledR}$ Probes. Arch Med Res 47: 142-145, 2016.

32. Sawyer SL, Tian L, Kähkönen M, Schwartzentruber J, Kircher M, Univeristy of Washington Centre for Mendelian Genomics; FORGE Canada Consortium, Majewski J, Dyment DA, Innes AM, et al: Biallelic mutations in BRCA1 cause a new Fanconi anemia subtype. Cancer Discov 5: 135-142, 2015.

33. Domchek SM, Tang J, Stopfer J,Lilli DR, Hamel N, Tischkowitz M, Monteiro AN, Messick TE, Powers J, Yonker A, et al: Biallelic deleterious BRCA1 mutations in a woman with early-onset ovarian cancer. Cancer Discov 3: 399-405, 2013.

34. Rebbeck TR, Friebel TM, Mitra N, Wan F, Chen S, Andrulis IL, Apostolou P, Arnold N, Arun BK, Barrowdale D, et al: Inheritance of deleterious mutations at both BRCA1 and BRCA2 in an international sample of 32,295 women. Breast Cancer Res 18: 112, 2016.

35. Howlett NG, Taniguchi T, Olson S, Cox B, Waisfisz Q, De Die-Smulders C, Persky N, Grompe M, Joenje H, Pals G, et al: Biallelic inactivation of BRCA2 in Fanconi anemia. Science 297: 606-609, 2002

36. Armour JA, Barton DE, Cockburn DJ and Taylor GR: The detection of large deletions or duplications in genomic DNA. Hum Mutat 20: 325-337, 2002.

37. Jeuken J, Cornelissen S, Boots-Sprenger S, Gijsen S and Wesseling P: Multiplex ligation-dependent probe amplification: A diagnostic tool for simultaneous identification of different genetic markers in glial tumors. J Mol Diagn 8: 433-443, 2006.

This work is licensed under a Creative Commons Attribution-NonCommercial-NoDerivatives 4.0 International (CC BY-NC-ND 4.0) License. 